\title{
SYNTHESIS, CHARACTERIZATION AND SORPTION PROPERTIES OF A SORBENT SYNTHESIZED USING SLAG AND RED MUD: ARSENIC REMOVAL FROM SPIKED AQUEOUS SOLUTIONS
}

\author{
PENTARI D. ${ }^{*}$ \\ ALEVIZOS G. \\ REPOUSKOU E. \\ KORELA S.
}

School of Mineral Resources Engineering, Technical University of Crete University Campus 73100 Chania, Crete, Greece

Received: 23/12/2015

Accepted: 19/01/2016

*to whom all correspondence should be addressed:

Available online: $12 / 05 / 2016$

e-mail: pentari@mred.tuc.gr

\section{ABSTRACT}

The aim of the present study was to synthesize a sorbent, for arsenic removal from aqueous solutions, reusing two waste materials (slag and red mud). The sorbent was prepared after chemical and thermal treatment, during which amorphous silica sol and $\mathrm{FeOOH}$ sol were produced simultaneously and form FeSi complexes on the surface of the slag. To characterize the sorbent Powder X-ray diffraction (XRD); Fourier transform infrared (FTIR) spectroscopy and Scanning Electron Microscopy (SEM-EDX) were applied. The surface area (BET method) and the Point of Zero Charge (PZC) of the sorbent were determined.). The sorption efficiency of the sorbent produced was investigated with kinetic and equilibrium studies, performed in batch conditions. The concentration of arsenic in solutions was determined by electro thermal atomic absorption spectroscopy (GF-AAS). The results of the study showed that with the described process, using metallurgical wastes, iron oxyhydroxides were "loaded" onto slag producing an effective sorbent for arsenic removal. Kinetic experiments proved that equilibrium was achieved within 15 hours, while the maximum adsorption capacity as evidenced by equilibrium experiments was $16.14 \mathrm{mg} \mathrm{g}^{-1}$. Data proved to fit better to the Langmuir equation.

Keywords: red mud, slag, iron oxyhydroxides, sorption, arsenic, waste water

\section{Introduction}

Several anthropogenic activities, such as mining, electric power generation from fossil fuels, ore smelting, and intensive cultivation, introduce arsenic in aquatic environments or soil. Regardless its source once mobilized arsenic tends to accumulate in living organisms, resulting in various diseases or disorders (Fu and Wang, 2011). Arsenic being toxic and carcinogen, is a hazard of prime interest and increasing significance; as far as surface and ground water are concerned, it can be considered among the chief pollutants. Several techniques have been proposed for arsenic removal from aqueous systems aiming in reducing its concentration in order to minimize impacts and meet strict legislative standards (WHO, 1993). Conventional techniques for the arsenic removal from aquatic environment such as ion exchange, chemical precipitation, membrane techniques, filtration, electrolytic or liquid extraction, and reverse osmosis (Fu and Wang, 2011; Qdais and Moussa, 2005; WHO, 1993) are in several cases technically complicated and/or economically unfavourable. Among the alternative techniques that have been developed for arsenic removal from aqueous systems sorption is very popular since it is both effective and inexpensive. Among the numerous substances (Dakiky et al., 2002; Gode and Pehlivan, 2005; Jochova 
et al., 2004; Karabulut et al., 2000; Kwon et al., 2010; Lacour et al., 2001, Pehlivan and Arslan, 2007) that have been tested as sorbents, iron oxides and oxyhydroxides, such as amorphous hydrous ferric oxide $(\mathrm{FeOOH})$, goethite $(\mathrm{a}-\mathrm{FeOOH})$, and hematite $\left(\mathrm{a}-\mathrm{Fe}_{2} \mathrm{O}_{3}\right)$, proved to be very effective (Raul et al., 2014, Gupta et al., 2010; Hua et al., 2012; Thirunavukkarasu et al., 2002). However, most iron oxides are very fine materials being, therefore, difficult to separate from the aqueous phase after treatment. To overcome this difficulty several researchers investigated the possibility of "loading" iron oxides and oxyhydroxides onto sand or slag Ilic et al., 2014, Martinez-Cabanas, 2015, Zhang and Itoh, 2005, Thirunavukkarasu et al., 2002) producing in that way a sorbent that can be easily separated from the aqueous phase.

The aim of this study is to test the "loading" of FeOOH on the surface of metallurgical slag, using red mud as iron source and producing in that way an effective sorbent, easy to handle. Both metallurgical slag and red mud are common metallurgical wastes. Some researchers have proposed a number of applications in order to recycle them, such as environmental remediation, metal recovery, and production of various materials including building materials, polymers and ceramics (Amorim et al., 2012; Bhatnagara et al, 2011; Costa et al., 2010; Liu et al., 2009; Liu and Zhang, 2011; Paramguru et al, 2005; Pontikes and Angelopoulos, 2013). The advantage of the procedure proposed in this study is quite obvious since it combines recycling with the synthesis of a high added value material, efficient for environmental remediation, contributing in that way to sustainable development. .

\section{Materials and methods}

\subsection{Materials}

The slag sample used in this study was electric arc furnace steel slag from Larco GMM S.A., Greece while the red mud sample used as iron source for the sorbent synthesis was obtained from Aluminium S.A., Greece. Both slag and red mud are characterized, according the Commission decision 2000/532/EC, as non-hazardous wastes. The metallurgical slag was crashed and sieved to a uniform size $(0.25-0.5 \mathrm{~mm})$ and dried at $105{ }^{\circ} \mathrm{C}$ for $24 \mathrm{~h}$ before use. The red mud was treated with concentrated $\mathrm{HCl}$ and $\mathrm{HNO}_{3}$ acids to produce the solution used as iron source for sorbent synthesis. By this digestion all red mud components except silica are dissolved and $\mathrm{Fe}(\mathrm{III})$ is expected to be the iron species in solution. All reagents used were of analytical grade. The chemical analysis of the two raw materials was performed by X-ray fluorescence (XRF) spectroscopy (S2 Ranger, Bruker). Crystalline compounds in slag were identified with an X-ray diffractometer (XRD) model D8 Advance of Bruker AXS, with application of $\mathrm{Cu}$ Ka radiation and nickel filter $(U=35 \mathrm{kV}, \mathrm{I}=35 \mathrm{~mA})$. The XRD scans were performed between 2 and $702 \theta^{\circ}$, with increments of $0.02^{\circ} \mathrm{s}^{-1}$. DIFFRAC plus Evaluation software system by Bruker AXS and JCPDS database were applied for data processing and identification of crystalline components. Morphology, texture, and composition of the metallurgical slag were studied by scanning electron microscopy (SEM-EDX, Jeol 5400) equipped with an energy dispersive X-ray analyzer (INCA energy 300). High vacuum evaporation (JEE-4X, Jeol) was applied to form a thin carbon film to make the surface of the specimens electrically conductive. The specific surface area of the slag was determined with Nova 2200 apparatus (Quantchrom), according to the BET method.

\subsection{Synthesis of the sorbent}

The sorbent (S-RM) was prepared after chemical and thermal treatment, described elsewhere (Fu et al., 2007; Swedlund and Webster, 2005; Zahng and Itoh, 2005) using as iron source the solution produced after acid treatment of the red mud. During the procedure amorphous silica sol and $\mathrm{FeOOH}$ sol are produced simultaneously forming, after treatment, Fe-Si complexes on the surface of the slag. The procedure followed was: $50 \mathrm{~g}$ of slag were contacted with $100 \mathrm{~mL}$ of $1 \mathrm{M} \mathrm{NaOH}$ for $2 \mathrm{~h}$ and aged at $80{ }^{\circ} \mathrm{C}$ for $48 \mathrm{~h}$. Then an iron solution, produced by the dissolution of red mud, containing $1 \mathrm{M}$ Fe was added until the $\mathrm{pH}$ value of the slurry was $\sim 7$. The slurry was magnetically stirred for $2 \mathrm{~h}$ and aged for $12 \mathrm{~h}$ at room temperature, then filtrated and heated at $105{ }^{\circ} \mathrm{C}$ for $2 \mathrm{~h}$ and then at $550{ }^{\circ} \mathrm{C}$ for $1 \mathrm{~h}$. Upon cooling the 
produced sorbent was vacuum-dried at $105{ }^{\circ} \mathrm{C}$ for $24 \mathrm{~h}$ and stored in a capped bottle. For comparison reasons another sorbent (S-I) was prepared using a $1 \mathrm{M} \mathrm{FeCl}_{3}$ solution as iron source, and following the same procedure; in addition, for the same purpose, amorphous FeOOH was prepared mixing $1 \mathrm{M} \mathrm{NaOH}$ and $1 \mathrm{M} \mathrm{FeCl}_{3}$ solutions, aging for $12 \mathrm{~h}$ and drying at $105^{\circ} \mathrm{C}$ for $24 \mathrm{~h}$.

\subsection{Sorbent characterization}

In order to compare S-RM with S-I their morphology, texture and composition were studied by scanning electron microscopy (SEM) using the equipment described for the slag, and crystalline compounds present in sorbents were determined by Powder X-ray diffraction (XRD) following the procedure described for the slag. In addition and for the same purpose Fourier transform infrared (FTIR) spectroscopy was applied and the complexes and the iron oxyhydroxides synthesized were identified. The FTIR spectra were obtained, in the range between 400 and $4000 \mathrm{~cm}^{-1}$, using the Spectrum 1000, spectrometer by Perkin Elmer, while the samples were pressed in discs after mixing with $\mathrm{KBr}$. The specific surface area of the sorbents was determined with Nova 2200 apparatus (Quantchrom), according to the BET method. The point of zero charge of the sorbents was measured based on the $\mathrm{pH}$ metric titration described by Babic et al. (1999).

\subsection{Sorption experiments}

The sorption capacity of the sorbents synthesized was examined with kinetic and equilibrium studies. The effect of contact time, and metal initial concentration on the sorption process were studied. All experiments were conducted in batch conditions using spiked aqueous solutions as sorbate. $\mathrm{Na}_{2} \mathrm{HAsO}_{4}$ (analytical grade) was used to prepare sorbates and $\mathrm{As}(\mathrm{V})$ is expected to dominate in the solution. All experiments were carried out in duplicate and mean values were used. Duplicate data differed from mean values by less than $2 \%$.

\subsubsection{Kinetic experiments}

Batch experiments were conducted, for both sorbents (S-I, S-RM), at room temperature $\left(25^{\circ} \mathrm{C}\right)$, in plastic containers, under continuous stirring. Sorbent dosage used was $5 \mathrm{~g} \mathrm{I}^{-1}$ and arsenic initial concentration was $100 \mathrm{mg} \mathrm{l}^{-1}$. At different time intervals $(0.2,0.5,1,2,12,15,24$, and $48 \mathrm{~h})$ the aqueous phase was withdrawn and filtered and the residual arsenic concentration, in the aqueous phase, was determined by flame atomic absorption spectroscopy (AAnalyst 100, Perkin Elmer). The analysis of arsenic in solutions produced after $48 \mathrm{~h}$ treatment of the sorbent samples with deionized water, showed that there was no leaching from the sorbents. Initial $\mathrm{pH}$ and $\mathrm{pH}$ values throughout the experiments were determined using a pH meter (model InolabLevel1, by WTW).

\subsubsection{Sorption Isotherms}

Sorption isotherm studies were conducted by varying the arsenic initial concentration from 1 to 100 $\mathrm{mg} \mathrm{l}^{-1}$ As $\left(1,3,5,10,20,50,80,100 \mathrm{mg} \mathrm{l}^{-1}\right)$. The sorption conditions were kept the same as in sorption kinetics and $15 \mathrm{~h}$ was chosen as contact time. This time was chosen since it was proved, by the kinetic experiments, to be sufficient for reaching equilibrium. The residual arsenic concentration in the aqueous phase was determined by electro thermal atomic absorption spectroscopy (HGA 800, AAnalyst 100, Perkin Elmer). MATLAB software was used to test the fitting of experimental equilibrium data to Langmuir and Freundlich equations.

\section{Results and discussion}

\subsection{Raw materials characterization}

The results of the XRF analysis for the raw materials are presented in Table 1. The metallurgical slag mainly contains $\mathrm{Ca}, \mathrm{Si}, \mathrm{Al}$, and $\mathrm{Fe}$. It is, therefore, anticipated that contacting the slag, which contains $35 \% \mathrm{SiO}_{2}$, with $\mathrm{NaOH}$ results in the formation of $\mathrm{Na}_{2} \mathrm{SiO}_{3}$, while the addition to the slurry of the acidic iron solution leads to the formation of Si-Fe surface complexes "loading" in that way iron oxyhydroxides on the metallurgical slag (Thirunavukkarasu et al., 2002; Zhang and Itoh, 2005). The red mud containing 42\% 
$\mathrm{Fe}_{2} \mathrm{O}_{3}$, on the other hand, can after dissolution produce an iron solution that can be used as the iron precursor for the sorbent formation.

Table 1. Content (\% oxides) of main elements in Slag and Red Mud.

\begin{tabular}{cllccc}
\hline & $\mathrm{CaO}$ & $\mathbf{S i O}_{\mathbf{2}}$ & $\mathbf{A l}_{\mathbf{2}} \mathbf{O}_{\mathbf{3}}$ & $\mathbf{M g O}$ & $\mathrm{Fe}_{\mathbf{2}} \mathbf{O}_{\mathbf{3}}$ \\
\hline Slag & 41 & 35 & 10 & 10 & 3 \\
\hline Red mud & 19 & 15 & 21 & 2 & 42 \\
\hline
\end{tabular}

The surface area of the slag proved being $0.13 \mathrm{~m}^{2} \mathrm{~g}^{-1}$. The surface morphology of the slag as evidenced by SEM characterization (Figure 1a) is glassy and in accordance with the extremely low surface area measured. Fayalite is the mineral identified by XRD since its three more intense peaks ( $d=2.830 \AA$, $d=2.500$ $\AA, d=1.775 \AA ̊$ ) are present in the corresponding XRD pattern. (Figure 2a).
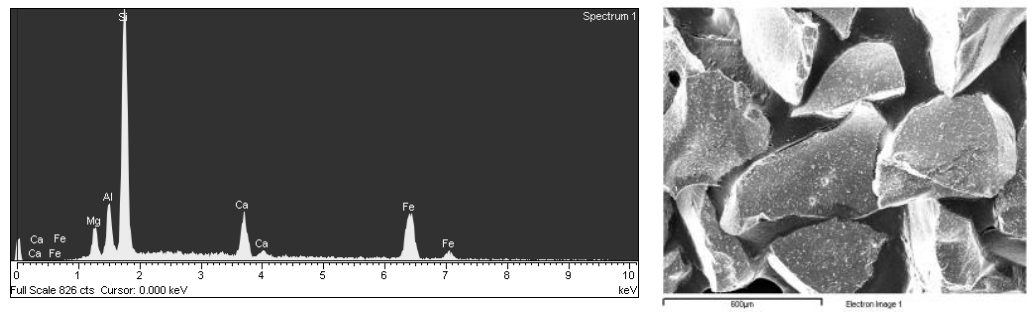

(a)
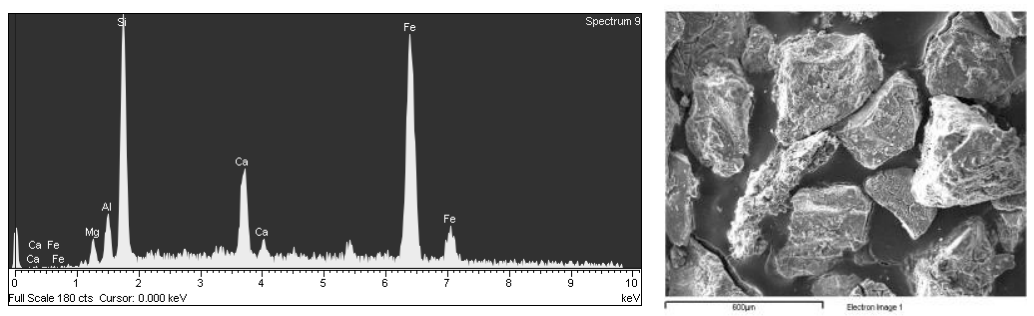

(b)
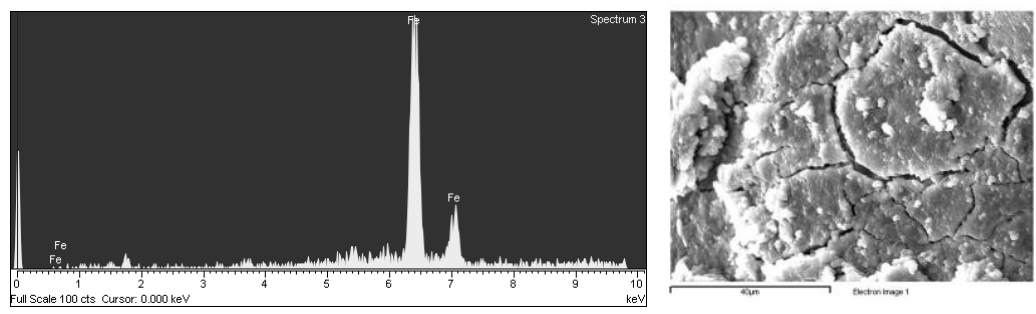

(c)

Figure. 1 SEM secondary image of the slag (a) and the sorbent S-RM ( $b$ and $c$ ) with corresponding EDS spectrum

\subsection{Sorbent characterization}

The morphology, texture and composition of the sorbents S-RM and S-I are identical as illustrated in Figures $1 \mathrm{~b}$ and $1 \mathrm{c}$, where the iron porous material loaded on the slag is depicted. The results of the mineralogical analysis of the sorbents (Figure $2 b)$ shows that apart from fayalite, goethite $(d=4.184 \AA$, $d=2.693 \AA, d=2.451 \AA$ ) is also present in the sorbents confirming that iron oxyhydroxides were successfully loaded onto the metallurgical slag. FTIR spectra obtained for slag, S-RM, S-I and oxyhydroxide (FeOOH) are presented in Figure 3. As it is well known (Bartzas and Komnitsas, 2010; Music et al., 1993; Strongin et al., 2010) the broad band centred at $3450 \mathrm{~cm}^{-1}$ that appears in the samples of the iron loaded slag and the $\mathrm{FeOOH}$, can be assigned to the stretching vibration of $-\mathrm{OH}$, while the IR band at $1637 \mathrm{~cm}^{-1}$ corresponds to the bending vibration of molecular water and hydrogen bonds. The bands between 400 and $600 \mathrm{~cm}^{-1}$ can be attributed to Fe-O bonds and, in the case of S-RM and S-I, to Fe-O-Si bonds. The oxyhydroxide sample clearly contains goethite since its typical bands at 890 and $798 \mathrm{~cm}^{-1}$ are present in the corresponding spectra while the broad band centred at $1050 \mathrm{~cm}^{-1}$, present in S-RM and S-I spectra, can be 
attributed to the overlapping of Fe-O-Si and ferrihydrite bands. The point of zero charge (PZC) and the surface area of the sorbents are reported in Table 2.

Table 2. Point of zero charge and surface area $\left(\mathrm{m}^{2} \mathrm{~g}^{-1}\right)$ of the sorbents

\begin{tabular}{ccc}
\hline & PZC & Surface Area $\left(\mathbf{m}^{\mathbf{2}} \mathbf{g}^{-1}\right)$ \\
\hline S-I & 8.4 & 12 \\
\hline S-RM & 8.1 & 10 \\
\hline
\end{tabular}

The PZC measured was 8.4 and 8.1 for S-I and S-RM, respectively, and is in accordance with values reported in literature for iron oxides and oxyhydroxides (Strongin et al., 2010). The surface area measured was 10 and $12 \mathrm{~m}^{2} \mathrm{~g}^{-1}$ for S-RM and S-I, respectively, which is within the range reported (Strongin et al., 2010; Zahng and Itoh, 2005) for both natural and synthetic iron oxides $\left(2-230 \mathrm{~m}^{2} \mathrm{~g}^{-1}\right)$. The elevated surface area of the sorbents compared to that of the slag can be attributed to the porous oxyhydroxides that have been loaded onto the slag during the synthesis process.

The above mentioned results point to the conclusion that with the proposed procedure iron oxides and oxyhydroxides were 'loaded' onto slag and that the sorbent prepared in this study, using red mud as the iron precursor, proved to have similar characteristics with the one that was prepared, for comparison purpose, using $\mathrm{FeCl}_{3}$ as iron source.

\subsection{Sorption experiments}

\subsubsection{Kinetic experiments}

Arsenic removal, by the sorbent S-RM, as a function of contact time is presented in Figure 4. The kinetic experiments showed that sorption capacity ( $\mathrm{mg} \mathrm{As} \mathrm{g}^{-1}$ sorbent) increased rapidly with increasing contact time, while the equilibrium was achieved within $15 \mathrm{~h}$ for all the batch experiments. Removal capacity proved to be $91 \%$ and $78 \%$ for S-I and S-RM sorbent, respectively. This is a significant difference, in accordance with the lower surface area measured for S-RM, which should be attributed to the fact that the sorbent was prepared using red mud as iron source. The $\mathrm{pH}$ value fluctuated throughout the experiments around 5.8. The effect of $\mathrm{pH}$ on the sorption process was not investigated. At pH $5.8 \mathrm{H}_{2} \mathrm{AsO}_{4}^{-}$ predominates while the surface of the sorbent, given its PZC at 8.1 or 8.4, is positively charged (Stumm and Morgan, 1995), it is therefore anticipated that experimental conditions favour $\mathrm{H}_{2} \mathrm{AsO}_{4}{ }^{-}$adsorption on the sorbent.

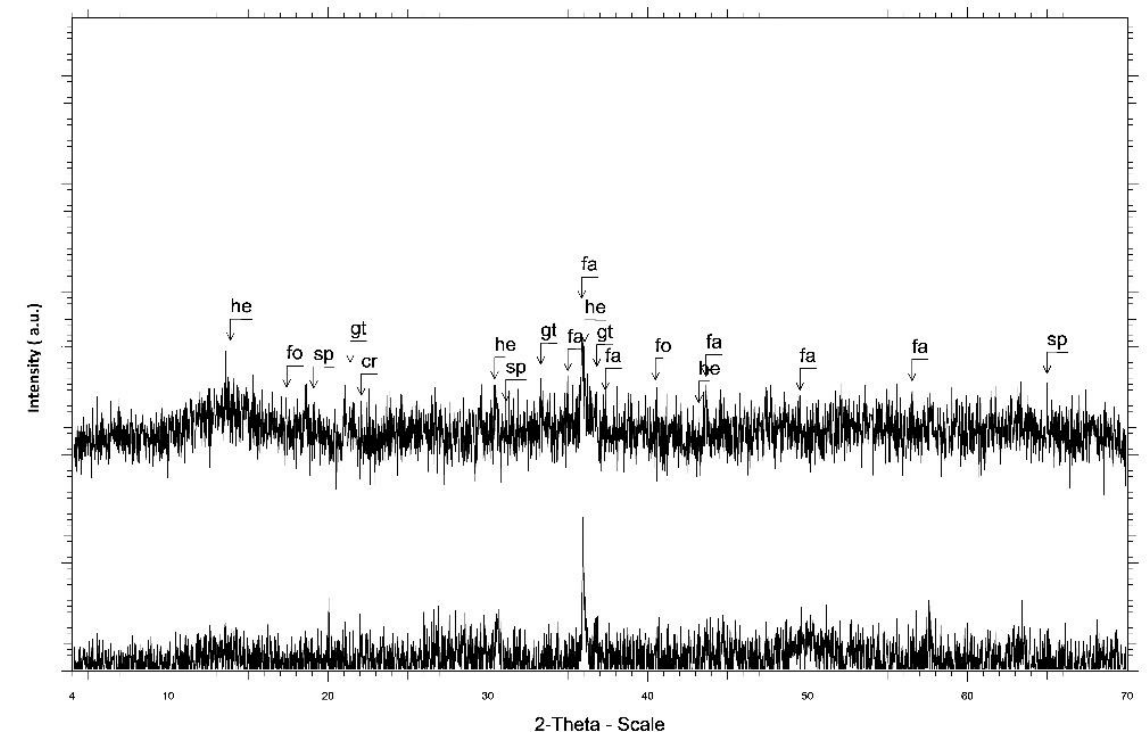

Figure 2. XRD analysis of S and S-RM. (gt: goethite, fa: fayalite, fo: forsterite, cr: cristobalite he: hedenbergite sp: spinel) 


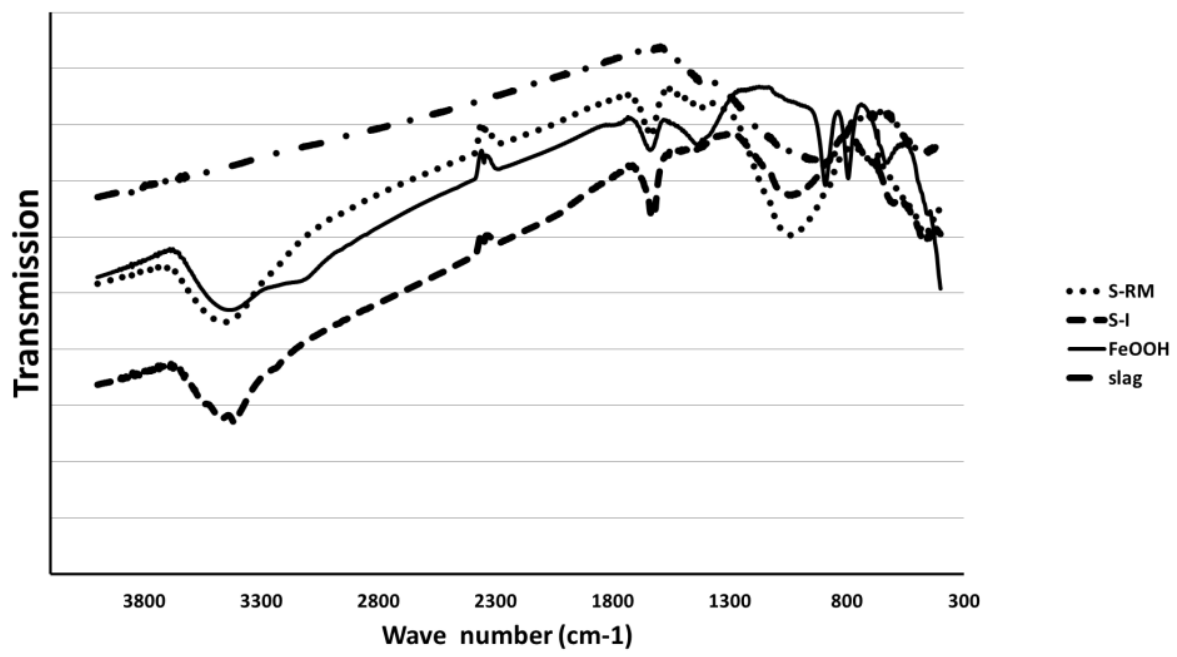

Figure 3. FT-IR spectra of sorbents S-RM and S-I, FeOOH and slag

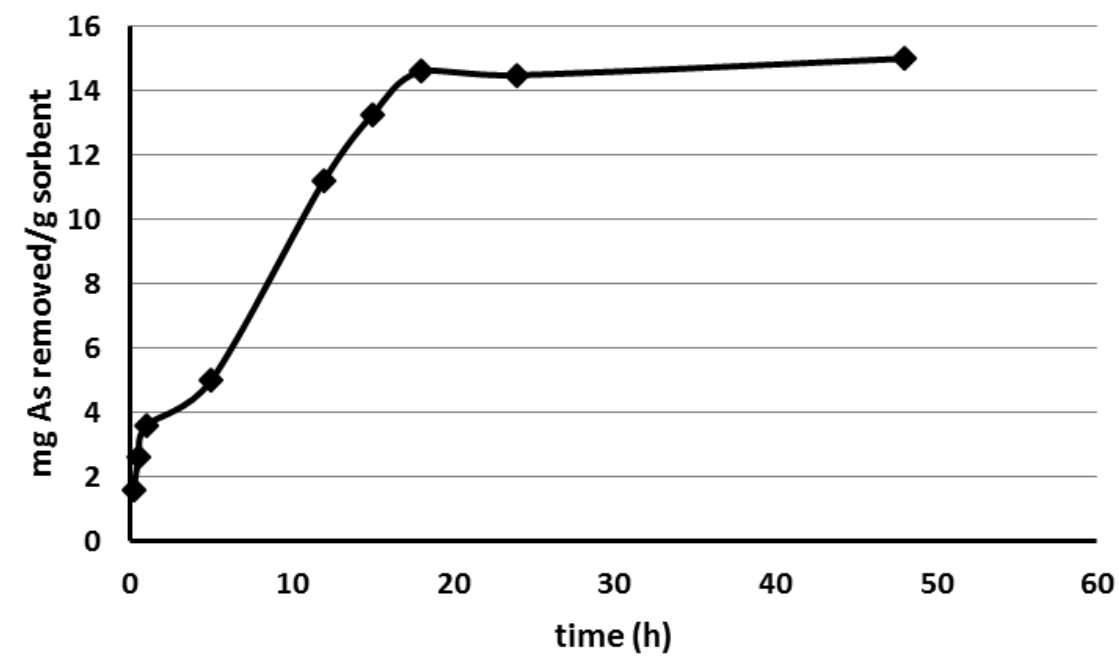

Figure 4. Sorption kinetics of arsenic sorption by sorbent S-RM. Experimental conditions: sorbent dosage $5 \mathrm{~g} \mathrm{I}^{-1}, \mathrm{pH} 5.8$, temperature $25^{\circ} \mathrm{C}$, As initial concentration $100 \mathrm{mg} \mathrm{l}^{-1}$

\subsubsection{Sorption isotherms}

The results of the equilibrium experiments are illustrated in Figure 5. The sorption isotherm may be considered of $\mathrm{H}$ or $\mathrm{L}$ type according to the classification of Giles et al. (1974), indicating that S-RM shows high affinity for the metals studied. To analyze the experimental equilibrium data and to obtain the maximum adsorption capacity of the sorbent, the Langmuir (Langmuir, 1918) and Freundlich (Freundlich, 1926) models are tested.

The equations used are:

$$
\begin{array}{ll}
\mathrm{q}=\mathrm{QmaxbCe} /(1+\mathrm{bCe}) & \text { (Langmuir) } \\
\mathrm{q}=\mathrm{KCe}^{1 / \mathrm{n}} & \text { (Freundlich) }
\end{array}
$$

where $\mathrm{q}$ is the amount of arsenic adsorbed per unit mass of sorbent, $\mathrm{Ce}$ is the cation concentration at equilibrium, Qmax is the maximum adsorption capacity; $K$ is related to the adsorption capacity and $\mathrm{b}, \mathrm{n}$ are constants related to adsorption intensity. For a non-linear regression, MATLAB software was used. 


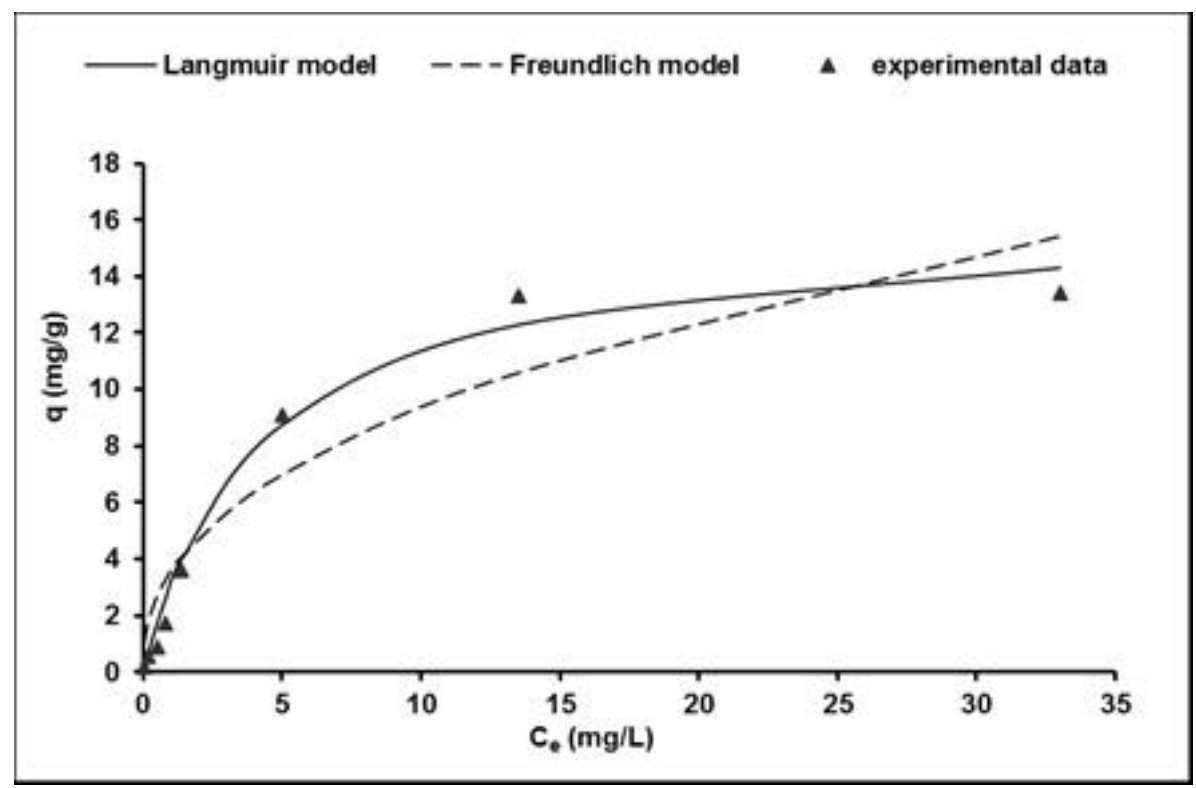

Figure 5 Sorption isotherm: predicted data vs experimental data. Lines represent predicted data by Langmuir and Freundlich models and symbols correspond to experimental data.

In Figure 5 both Langmuir and Freundlich fits for As are presented and it is concluded that experimental data of the present work is better fitted to the Langmuir equation than the Freundlich one, since the correlation coefficient calculated for the Langmuir equation is higher than that for the Freundlich equation (Table 3). This suggests that the arsenic sorption by the synthesized sorbent follows the Langmuir model and that the adsorption process could be described by the formation of a monolayer coverage of the adsorbate on adsorbent surface. The maximum adsorption capacity calculated by the Langmuir equation is $16.14 \mathrm{mg} \mathrm{g}^{-1}$. This adsorption capacity is comparable to those reported in literature for various arsenic sorbents and higher than sorption capacities exhibited by other waste materials that have been proposed as arsenic sorbents (Martinez-Cabanas et al.,2015, Ilic et al., 2014, Raul et al., 2014, Salem Attia et al, 2014, Hua et al., 2012; Huijie et al., 2009; Jovanovic and Rajakovic, 2010; Mohan and Pittman, 2007; Thirunavukkarasu et al., 2002; Zahng and Itoh, 2005).

Table 3. Langmuir and Freundlich constants from sorption isotherms at $25^{\circ} \mathrm{C}$.

\begin{tabular}{|c|c|c|c|c|c|}
\hline \multicolumn{3}{|c|}{ Langmuir } & \multicolumn{3}{|c|}{ Freundlich } \\
\hline Qmax (mg g $\left.{ }^{-1}\right)$ & $B\left(\mathrm{~L} \mathrm{mg}^{-1}\right)$ & $r^{2}$ & $K$ & $\mathrm{n}$ & $r^{2}$ \\
\hline 16.14 & 0.24 & 0.985 & 3.53 & 2.37 & 0.894 \\
\hline
\end{tabular}

\section{Conclusions}

The results of the present study show that iron oxyhydroxides are successfully loaded onto the metallurgical slag, leading to the synthesis of an effective and easy to handle sorbent for arsenic removal from aqueous systems. Red mud can be used as iron source, since the two sorbents S-RM and S-I synthesized in the present study, have similar characteristics and performance. The kinetic experiments show that equilibrium is achieved within $15 \mathrm{~h}$ and the maximum sorption capacity calculated by the Langmuir equation is $16.14 \mathrm{mg} \mathrm{g}^{-1}$. The experimental data is better fitted to the Langmuir equation than the Freundlich one suggesting that the arsenic sorption by the synthesized sorbent could be described by the formation of a monolayer coverage of the adsorbate on adsorbent surface. The sorption capacity, $16.14 \mathrm{mg} \mathrm{g}^{-1}$, of S-RM is comparable to those reported in literature for various arsenic sorbents and higher than sorption capacities exhibited by other waste materials proposed as arsenic sorbents.

Work is in progress with arsenic speciation and desorption studies. Additionally, the effect of $\mathrm{pH}$ on the sorption process has to be investigated in order to identify the sorption process mechanism and optimize 
the whole procedure to design pilot scale or field scale projects. Nevertheless the advantage of the procedure proposed is quite obvious since it combines recycling with the synthesis of a high added value material, efficient for environmental remediation, contributing in that way to sustainable development.

\section{References}

Amorim C., Dutra P., Leao M., Pereira M., Henriques A., Fabris J. and Lago R. (2012), Controlled reduction of steel waste to produce active iron phases for environmental applications, Chemical Engineering Journal, 209, 645-651.

Babic B., Milorjic S., Polovina M. and Koludieronic B. (1999), Point of zero charge and intrinsic equilibrium constants of activated carbon cloth, Carbon, 37, 477-480.

Bartzas G. and Komnitsas K. (2010), Solid phase and geochemical modelling of low-cost permeable reactive barriers, Journal of hazardous materials, 183, 301-308.

Bhatnagara A., Vilara V., Botelhoa C. and Boaventuraa R. (2011), A review of the use of red mud as adsorbent for the removal of toxic pollutants from water and wastewater, Environmental Technology, 32(3), 231-249.

Costa R., Moura F., Oliveira P., Magalhaes F., Ardisson J. and Lago R. (2010), Controlled reduction of red mud waste to produce active systems for environmental applications: Heterogenous Fenton reaction and reduction of $\mathrm{Cr}$ (VI), Chemosphere, 78, 1116-1120.

Dakiky M., Khamis M., Manassra A. and Mer'eb M. (2002), Selective adsorption of chromium (VI) in industrial wastewater using low-cost abundantly available adsorbents, Advances in Environmental Research, 6, 533-540.

Freundlich H. (1926), Colloid and Capillary Chemistry, Methuen and Co. Ltd., London,

Fu Y., Yu S., Yu Y., Qiu L. and Hui B. (2007), Reaction mode between Si and Fe and evaluation of optimal species in polysilicicferric coagulant, Journal of Environmental Sciences, 19, 678-688.

Fu F.L. and Wang Q. (2011), Removal of heavy metal ions from wastewaters: a review, Journal of Environmental Management, 92, 407-418.

Giles C.H., Smith D. and Huitson A. (1974), A general treatment and classification of the solute adsorption isotherm, Journal colloid interface Science, 47, 755-766.

Gode F. and Pehlivan E. (2005), Adsorption of $\mathrm{Cr}$ (III) ions by Turkish brown coals, Fuel Processing Technology, 86, 875-844.

Gupta K., Maity A. and Ghosh U.C. (2010), Manganese associated nanoparticles agglomerate of iron (III) oxide: Synthesis, characterization and arsenic (III) sorption behaviour with mechanism, Journal of hazardous materials, 184, 832-842.

Hua M., Zhang S., Pan B., Zhang W., Lv L. and Zhang Q. (2012), Heavy metal removal from water/waste water by nanosized metal oxides, A review, Journal of hazardous materials, 211-212, 317-331.

Huijie Z., Yongfeng J., Xing W. and He W. (2009), Removal of arsenic from water by supported nano zero-valent iron on activated carbon, Journal of Hazardous materials, 172, 1591-1596.

Ilic N.I., Lazarevic S.S., Rajakovic-Ognjanovic V.N., Rajakovic L.V., Janackovic D.T. and Petrovic R.D. (2014), The Sorption of Inorganic Arsenic on Modified Sepiolite: The Effect of Hydrated Iron(III) Oxide, Journal of the Serbian Chemical Society, 79(7), 815-828.

Jochova M., Puncochar M., Horacek J., Stamberg K. and Vopalka D. (2004), Removal of heavy metals from water by lignite-based sorbents, Fuel, 83, 1197-1203.

Jovanovic B.M. and Rajakovic L.V. (2010), New approach: Waste materials as sorbents for arsenic removal from water, Journal of environmental Engineering, 136(11), 1277-1286.

Karabulut S., Karabakan A., Denizli A. and Yurum Y. (2000), Batch removal of copper(II) and zink(II) from aqueous solutions with low rank Turkish coals, Separation and Purification Technology, 18, 177-184.

Kwon J., Yun S., Lee J., Kim S. and Youngjo H. (2010), Removal of divalent heavy metals and arsenic (III) from aqueous solution using scoria: Kinetics and equilibria of sorption, Journal of hazardous materials, 174, 307-313. 
Lacour S., Bollinger J.C., Serpaud B., Chantron P. and Arcos R. (2001), Removal of heavy metals in industrial wastewaters by ion-exchanger grafted textiles, Analytica Chimica Acta, 428, 121-132.

Langmuir I. (1918), The adsorption of gases on plane surfaces of glass, mica and platinum, Journal of American Chemical Society, 40, 1361-1403.

Liu W., Yang J. and Xiao B. (2009), Application of Bayer red mud for iron recovery and building material production from alumosilicate residues, Journal of Hazardous Materials, 161, 474-478.

Liu X. and Zhang N. (2011), Utilization of red mud in cement production: A review, Waste Management and Research, 29, 1053-1063.

Martínez-Cabanas, M., Carro L., López-García M., Herrero R., Barriada J.L. and Sastre de Vicente M.E. (2015), Achieving Sub-10ppb Arsenic Levels with Iron Based Biomass-Silica Gel Composites, Chemical Engineering Journal, 279, 1-8.

Mohan D. and Pittman Jr C.U. (2007), Arsenic removal from water/wastewater using adsorbents: A critical review, Journal of Hazardous Materials, 142(1-2), 1-53.

Music S., Gotic M. and Popovic S. (1993), X-ray diffraction and Fourier transform-infrared analysis of the rust formed by corrosion of steel in aqueous solutions, Journal of material science, 28, 5744-5752.

Paramguru R.K., Rath P.C. and Misra V.N. (2005), Mineral Processing and Extractive Metallurgy, Review, Trends in red mud utilization, 26(1), 1-29.

Pehlivan E. and Arslan G. (2007), Removal of metal ions using lignite in aqueous solution - Low cost biosorbents, Fuel Processing Technology, 88, 99-106.

Pontikes Y. and Angelopoulos G.N. (2013), Bauxite residue in cement and cementitious applications: Current status and a possible way forward Review, Resources, Conservation and Recycling, 73, 53-63.

Qdais H.A. and Moussa H. (2004), Removal of heavy metals from waste water by membrane processes: a comparative study, Desalination, 164(2), 105-110.

Raul, P.K., Devi R.R., Umlong I.M., Thakur A.J., Banerjee S. and Veer V. (2014), Iron Oxide Hydroxide Nanoflower Assisted Removal of Arsenic from Water, Materials Research Bulletin, 49(1), 360-368.

Salem Attia T.M., Hu X.L and Yin D.Q. (2014), Synthesized Magnetic Nanoparticles Coated Zeolite (MNCZ) for the Removal of Arsenic (as) from Aqueous Solution, Journal of Experimental Nanoscience, 9(6), 551-560.

Strongin D., Grey C.P., Parise J. and Kubicki J. (2010), Surface science studies of environmentally relevant iron (oxy)hydroxides ranging from the nano to the macro-regime, Surface science, 604, 1065-1071.

Stumm W. and Morgan J. (1995) Aquatic chemistry Wiley $3^{\text {rd }}$ edition

Swedlund P. and Webster J. (2005), Adsorption and polymerization of silicic acid on ferrihydrite, and its effect on arsenic adsorption, Water research, 33, 3413-3422.

Thirunavukkarasu O., Viraraghavan T. and Subramanian K.S. (2002), Arsenic removal from drinking water using iron oxide coated sand, Water, Air, and Soil Pollution, 142, 95-111.

WHO (1993) Guidelines for drinking water quality. Recommendations $2^{\text {nd }}$ ed., World Health organization.

Zhang F. and Itoh H. (2005), Iron oxide-loaded slag for arsenic removal from aqueous system, Chemoshere, 60, 319-325. 